\title{
Self-assembled diphenylalanine peptide microtubes covered by reduced graphene oxide/spiky nickel nanocomposite: An integrated nanobiomaterial for multifunctional applications
}

\author{
M.S. Ivanov ${ }^{\mathrm{a}, \mathrm{e}, *}$, V.A. Khomchenko ${ }^{\mathrm{a}}$, M. Salimian ${ }^{\mathrm{b}}$, T. Nikitin ${ }^{\mathrm{c}}$, S. Kopyl ${ }^{\mathrm{d}}$, A.M. Buryakov ${ }^{\mathrm{e}}$, E.D. Mishina ${ }^{\mathrm{e}}$, \\ F. Salehli ${ }^{\text {, }}$ P.A.A.P. Marques ${ }^{\text {b }}$, G. Goncalves ${ }^{\text {b }}$, R. Fausto ${ }^{\text {c }}$, J.A. Paixão ${ }^{\text {a }}$, A.L. Kholkin ${ }^{\text {d,g }}$ \\ a CFisUC, Department of Physics, University of Coimbra, 3004-516 Coimbra, Portugal \\ b TEMA-NRD, Mechanical Engineering Department, University of Aveiro, 3810-193 Aveiro, Portugal \\ c CQC, Department of Chemistry, University of Coimbra, 3004-535 Coimbra, Portugal \\ d CICECO-Aveiro Institute of Materials, Department of Physics, University of Aveiro, 3810-193 Aveiro, Portugal \\ e Moscow Technological University MIREA, Vernadskogo Ave. 78, 119454 Moscow, Russia \\ ${ }^{\mathrm{f}}$ Department of Physics Engineering, Istanbul Technical University, Maslak, 34469, Istanbul, Turkey \\ g School of Natural Sciences and Mathematics, Ural Federal University, 620000 Ekaterinburg, Russia
}

\section{H I G H L I G H T S}

- Peptide microtubes (PMTs) integrated with nickel nanoparticles-decorated rGO were for the first time fabricated.

- rGO/Ni composite forms planar electrode-like layer on PMT surface and induces a 100 -fold increase in electrical conductivity.

- A two-fold increase in mechanical stiffness of the microtubes was revealed.

- The appearance of a strong piezoresponse (with vertical and lateral piezo-coefficients of $12 \mathrm{pm} / \mathrm{V}$ and 18 $\mathrm{pm} / \mathrm{V}$ ) was found.

\section{A R T I C L E I N F O}

\section{Article history:}

Received 3 November 2017

Received in revised form 8 January 2018

Accepted 9 January 2018

Available online 10 January 2018

\section{Keywords:}

Diphenylalanine (FF) peptide microtubes

Reduced graphene oxide

Nickel nanoparticles

Bio-nanocomposites

Scanning Probe Microscopy
G R A P H I C A L A B S T R A C T

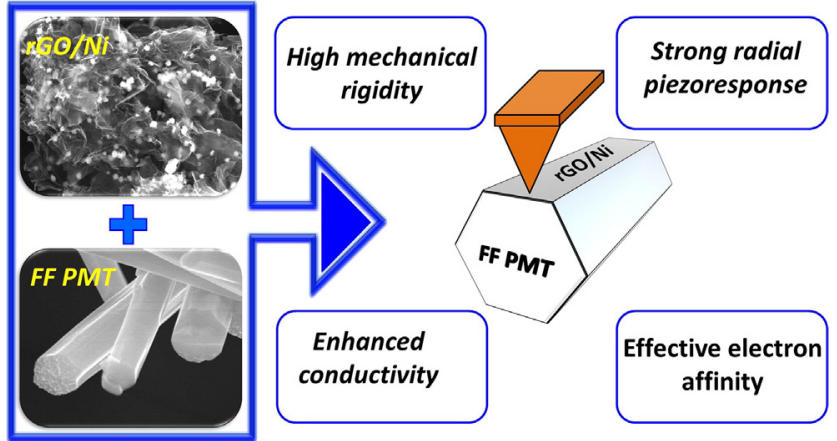

\begin{abstract}
A B S T R A C T
In this work we report macroscopic integration of reduced graphene oxide decorated by nickel nanoparticles ( $\mathrm{rGO} / \mathrm{Ni}$ ) with self-assembled diphenylalanine (FF) peptide microtubes (PMTs). The rGO/Ni nanocomposite forms planar electrode-like structure on the FF PMT surface and improves its mechanical and physical characteristics, as evidenced by the electron and scanning probe microscopy techniques. In particular, the enhancement of helical structural stability and stiffness of PMTs in the presence of rGO/Ni has been found. The interaction between $\mathrm{rGO} / \mathrm{Ni}$ and FF PMTs modifies electromechanical properties of the microtubes, so that a large radial piezoresponse untypical of the pristine FF PMTs appears. Furthermore, the introduction of $\mathrm{rGO} / \mathrm{Ni}$ enhances electrical conductivity of FF PMTs. The energy diagram of the PMT/rGO/Ni structure suggests an easy path for the optical conversion and light energy harvesting. The technical approach considered in this work opens up a new
\end{abstract}

\footnotetext{
* Corresponding author at: CFisUC, Department of Physics, University of Coimbra, P-3004-516 Coimbra, Portugal.

E-mail address: maxim.ivanov@uc.pt (M.S. Ivanov).
} 
Local current

Mechanical properties

Energy harvesting perspective for the fabrication of macroscopic-scale integrated rGO/Ni and FF PMTs allowing a variety of functional bio-nanostructures to be designed.

(c) 2018 Elsevier Ltd. All rights reserved.

\section{Introduction}

Dedicated synthesis towards well-ordered arrays of functional molecules or building blocks is one of the ultimate challenges for nanotechnology, biology and materials science, especially for energy harvesting applications [1]. Self-assembly is a preferred highly effective method to create a desirable architecture via supramolecular organization which matches the basic requirements for integrated artificial synthetic systems [1-6]. Bioinspired artificial synthetic systems based on self-assembled dipeptides and graphene oxide (GO) have been recently recognized as very promising since they provide a link between bionanotechnology and microelectronics and suggest multiple applications in energy harvesting, biosensing, magnetically controlled drug delivery and other fields [4-6]. Both materials, self-assembled dipeptides and GO, have been a subject of intensive studies, however, there is still a great challenge for practical applications likely due to the lack of effective control of their structure as well as the lack of understanding of the self-assembly mechanisms and basic functional properties [4-7]. Our recent studies [7] have demonstrated successful fabrication of reduced graphene oxide/nickel (rGO/Ni) composites having a range of desired properties for multifunctional applications. It has been shown [7] that significant improvement of conductive properties of rGO matrix decorated by nickel nanoparticles as compared with the pure rGO matrix can be achieved. Similar results have been reported by Lu et al., where they demonstrated the decoration of rGO matrix by Au nanoparticles and $\beta$-lactoglobulin (BLG), after which the BLG-rGO/ Au hybrid system acquired high efficiency as Surface Enhanced Raman Scattering (SERS) substrate and might be used in SERS-based technology [8].

One of the powerful strategies for $\mathrm{rGO} / \mathrm{Ni}$ manipulation is a covalent chemistry $[9,10]$ and noncovalent modification [11] allowing reversibility and structural integrity. It is thought that incorporation of $\mathrm{rGO} / \mathrm{Ni}$ into biomolecular materials could be a perspective approach to increase the application range of graphene-based materials. This is especially important for self-assembled FF dipeptides - supramolecular polymers formed by the stacking of appropriate cyclic peptides via hydrogen bonds $[12,13]$. The straightforward synthesis of self-assembled dipeptides (which found applications ranging from ion separation to electroactive molecule temptation and antimicrobial therapy [13-15]) is a major advantage allowing the complete control of ring diameter and side chain to be attained. Among all dipeptides, the diphenylalanine (FF) is the most used serving as a model of bio-inspired dipeptides, which play a crucial role in the formation of $\beta$ amyloid fibril form factor due to the $\pi-\pi$ stacking $[16,17]$. Recently, it has been shown that FF dipeptides in a form of micro- and nanotubes display excellent optical and electrical performance, such as light-induced ferroelectricity for information storage [18] and piezoelectricity for future generation of "green" nanopiezoelectrics [19]. In general, FF can be chemically modified via its carboxyl group or its amino group [20-22] as well as adapted by connecting responsive groups such as photo-responsive or bi-functional direct groups (-SH, Boc, Fmoc, etc.), thus attaining required functionality. For instance, Park and co-workers have designed lightharvesting nanotubes, self-assembled from a combination of FF and tetra(phydroxyphenyl) porphyrin (THPP) molecules, for artificial photosynthesis [22].

To explore whether practical performance of dipeptide microtubes could be further improved via their integration with graphene-based materials, fabrication and extensive scanning probe microscopy study of PMT/rGO/Ni structures was for the first time performed. Significant enhancement of mechanical, electrical and piezoelectric properties of FF PMTs in the presence of rGO/Ni composite was revealed. Results of this work suggest that the concept of the hybrid bioinspired artificial synthetic systems demonstrating high electron affinity and providing natural planar electrode-like covering of PMT surface can be used for designing various applications in the fields of energy harvesting, biosensing and embedded microelectronics.

\section{Experimental}

\subsection{Synthesis of the samples}

The diphenylalanine samples were fabricated by a common precipitation preparation method. For this purpose, the lyophilized form of the diphenylalanine (H-D-Phe-D-Phe-OH, FF) peptide (Bachem, Bubendorf, Switzerland) and the solvent 1,1,1,3,3,3-hexafluoro-2-propanol (HFIP, Sigma-Aldrich) were used. During the sample fabrication procedure, a fresh peptide stock solution was prepared by dissolving the peptide powder in $100 \mathrm{mg} / \mathrm{ml}$ of HFIP. To avoid pre-aggregation, fresh stock solutions were prepared before each test. Further, GO solution was prepared by chemical exfoliation of graphite powder (size $<45 \mu \mathrm{m}$, purity $>99.99 \%$, Sigma-Aldrich) following the modified Hummers method [11]. Synthesis of rGO/Ni nanocomposite was performed according to previously reported work [7]. Briefly, a $10 \mathrm{ml}$ of GO solution $(1 \mathrm{mg} / \mathrm{ml})$ was mixed with a solution of $\mathrm{Ni}\left(\mathrm{NO}_{3}\right)_{2}(0.07 \mathrm{~mol} / \mathrm{l})$ and hydrazine $(0.83 \mathrm{~mol} / \mathrm{l})$. The mixture was transferred to a $25 \mathrm{ml}$ Teflon autoclave for thermal treatment during $22 \mathrm{~h}$ at $100{ }^{\circ} \mathrm{C}$. Finally, the nanocomposite material obtained was extensively washed by filtration with distillated water and lyophilized. In this work, we have used the step by step sample preparation method, where at first step $2 \mu \mathrm{l}$ of FF stock solution was dropped on Pt substrate and then $98 \mu$ of distilled water ( $\mathrm{pH}$ 6.67) was added. These concentrations result in FF PMTs final sample, which was dried at room temperature for one day. The concentration of $\mathrm{rGO} / \mathrm{Ni}$ can be controlled by the solution concentration during the mixing procedure, so the required configuration of the composite can be achieved. Hence, $25 \mu \mathrm{l}$ of prepared $\mathrm{rGO} / \mathrm{Ni}$ solutions with different concentrations $(0.05,0.1,0.15$ and $0.2 \mathrm{mg} / \mathrm{ml})$ were dropped on the FF PMTs sample and again dried at room temperature for one day. Scanning electron microscopy (SEM) images of the samples obtained are displayed in Fig. 1 and Figs. S1 and S2 (ESI). The $0.15-0.2 \mathrm{mg} / \mathrm{ml}$ concentrations of $\mathrm{rGO} / \mathrm{Ni}$ give rise to the composite-excessive configurations shown in Fig. 1(a) and Fig. S1 (ESI). An optimal concentration assuring the deposition of $\mathrm{rGO} / \mathrm{Ni}$ on single FF PMTs has been found to be close to $0.1 \mathrm{mg} / \mathrm{ml}$ (Fig. 1(b, c, e); for the concentration of $0.05 \mathrm{mg} / \mathrm{ml}$ (image not shown), almost no coverage of $\mathrm{rGO} / \mathrm{Ni}$ on pristine PMTs has been seen). The fact that rGO/Ni layer is distinguished by a dark contrast in the secondary electron (SE) SEM images (thus expectedly indicating that $\mathrm{rGO} / \mathrm{Ni}$ is more conductive as compared to FF PMTs) is confirmed by corresponding backscattered electron (BSE) images demonstrating a brighter contrast expected for a heavier elemental composition of rGO/Ni layer) (Fig. 1 and Figs. S1 and S2 (ESI)). The comparison of SEM images of pristine FF PMTs and those covered by the $\mathrm{rGO} / \mathrm{Ni}$ composite indicates that this type of color gradient is not normally present in pure peptide microtubes (Fig. S2 (ESI)). Taking into account the SEM data, we suppose that $\mathrm{rGO} / \mathrm{Ni}$ composite is deposited on top of upper PMT's hexagonal facet (a SEM image of pristine FF PMT hexagonal face is presented in Fig. S2(a) (ESI)), as schematically shown in Fig. 1(d). 

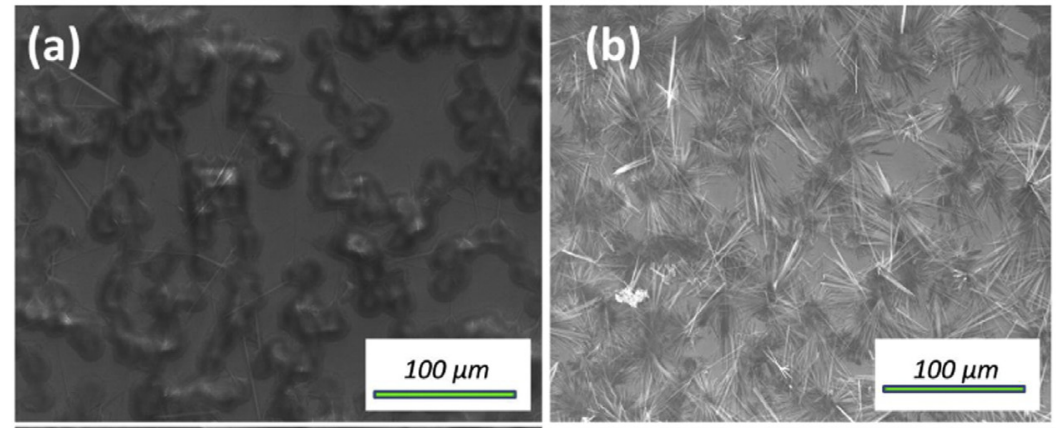

\section{$100 \%$}
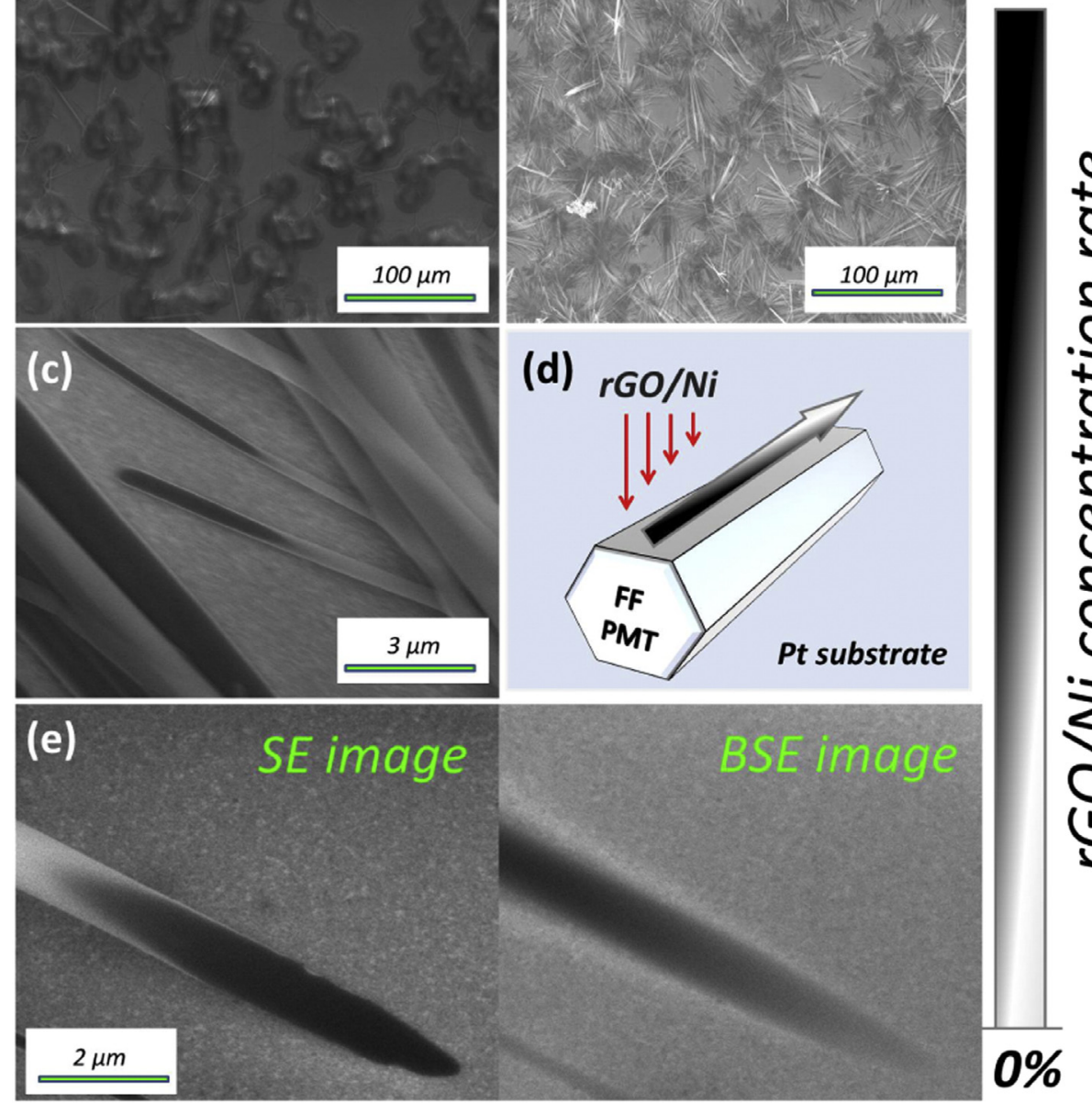

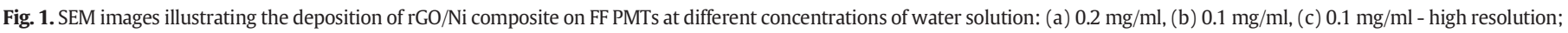
(d) schematic view of rGO/Ni gradient layer on top of FF PMT; (e) the SE and BSE SEM images of rGO/Ni gradient layer on top of FF PMT.

The image illustrates that the rGO/Ni concentration is typically maximal near the end of peptide microtube and decreases while moving towards the tube's center.

\subsection{Characterization procedure}

The powder and single crystal X-ray diffraction (XRD) data were collected using a Siemens D5000 and a Bruker D8 QUEST diffractometers, respectively. Microstructural analysis was done by using scanning electron microscopes HR-FESEM SU-70 (Hitachi) and VEGA-3 SB (TESCAN) operating at an accelerating voltage of $15-20 \mathrm{kV}$ and equipped with secondary electron and backscattered electron detectors. Unpolarized Raman spectra excited by a 532-nm laser radiation were recorded with a Horiba LabRAM HR Evolution Raman microscope using 50× and $100 \times$ objectives in the range of $500-3400 \mathrm{~cm}^{-1}$. The nanoscale properties were characterized by commercial scanning probe microscope (Ntegra Aura, NT-MDT) using several modes: c-AFM for local current measurements, EFM and KPFM for electrostatic field and surface potential distribution measurements, PFM for local piezoelectric properties measurements, and advanced Hybrid mode (NT-MDT ${ }^{\mathrm{TM}}$ ) for local mechanical property evaluation. During the measurements, a number of different probes were used according to the specific mode and in order to enhance the signal to noise ratio. In particular, PPPEFM-20 (resonance frequency $45-115 \mathrm{kHz}$, force constant $0.5-9.5 \mathrm{~N} /$ $\mathrm{m}$, NANOSENSORS) cantilevers were used for EFM and KPFM measurements, NSG01 (resonance frequency $87-230 \mathrm{kHz}$, force constant 1.45$15.1 \mathrm{~N} / \mathrm{m}$, NT-MDT) cantilevers were used for AFM, PFM, and Hybrid mode measurements and NSG10Pt (resonance frequency 140-390 $\mathrm{kHz}$, force constant 3.1-37.6 N/m, NT-MDT) cantilevers were used for c-AFM measurements. The bias voltage applied to the sample during the measurements varied in the range of 1-10 Volts; the PFM measurements were done under applied $a c$ voltage with an amplitude $V_{\mathrm{ac}}=5 \mathrm{~V}$ and a frequency $f=50 \mathrm{kHz}$. The PFM response signal intensity calibration was based on a calibration procedure performed with the reference PPLN (PFM03, NT-MDT) sample at ambient conditions (room temperature, relative humidity 30\%). KPFM technique was used to measure work function (WF) difference between the tip and the sample according to the equation

$V_{C P D}=\frac{W_{\text {tip }}-W_{\text {sample }}}{-e}$

where $W_{\text {tip }}$ is the WF of the SPM tip coating, $W_{\text {sample }}$ is the WF of the sample, $e$ is the elementary charge, $V_{C P D}$ is the measured contact potential difference, viz. surface potential. The $A C$ voltage of the second pass was $1 \mathrm{~V}$, the lift height was $20 \mathrm{~nm}$. We used Pt/Ir coated cantilever that was calibrated on a sputtered Pt thin film. Calibration and measurements were performed under ambient conditions (room temperature, relative humidity $~ 30 \%$ ).

\section{Results and discussion}

The structural and intermolecular properties of the PMT/rGO/Ni sample were characterized by XRD and micro-Raman spectroscopy 


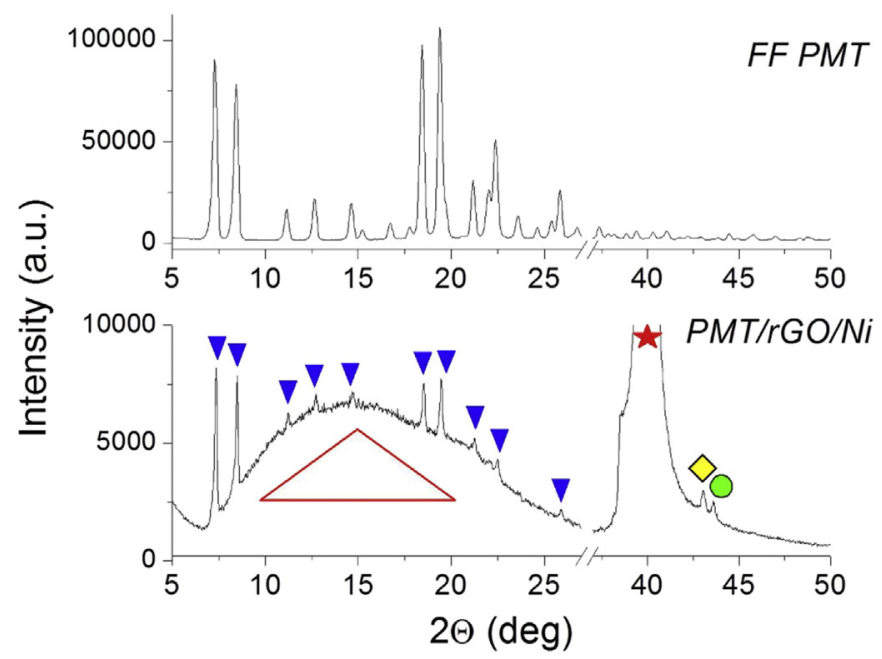

Fig. 2. The experimental XRD patterns for pristine self-assembled FF peptide microtubes and $\mathrm{PMT} / \mathrm{rGO} / \mathrm{Ni}$ structure. Blue filled and red open triangles indicate the peaks coming from FF PMTs and rGO, respectively. The reflection indicated by red star is due to platinum substrate. Yellow rhomb and green circle indicate the peaks associated with partly-oxidized Ni nanoparticles.

techniques. Fig. 2 shows the XRD pattern obtained for the pristine FF PMTs and PMT/rGO/Ni complex. The pristine FF microtubes were investigated using single crystal and powder X-ray diffraction, whose results were in good agreement with each other. The obtained lattice parameters were: $\mathrm{a}=\mathrm{b}=24.09 \AA, \mathrm{c}=5.46 \AA, \alpha=\beta=90^{\circ}$, and $\gamma=120^{\circ}$. All observed XRD peaks of FF PMTs correspond to the expected hexagonal structure already reported for FF PMTs and PNTs: $\mathrm{a}=\mathrm{b}=24.071 \AA$ A $\mathrm{c}$ $=5.456 \AA$ [12]. The diffraction pattern of PMT/rGO/Ni complex contains the peaks which are fully consistent with those specific to pure diphenylalanine peptide (blue filled triangles in Fig. 2) [12], a broad peak associated with the rGO matrix (red open triangle in Fig. 2) [23], a peak with the maximum intensity from the Pt substrate (red star in Fig. 2) [23, 24], and peaks related to the Ni nanoparticles (yellow rhomb and green circle) [25]. These results imply that deposition of rGO/Ni composite does not change the hexagonal structure of FF PMTs.

Raman spectroscopy was implemented as a versatile non-destructive tool widely used for studying graphene-containing structures $[2$, 26-31]. Fig. S3 (ESI) presents Raman spectra of the PMTs/rGO/Ni sample excited by $532-\mathrm{nm}(2.33 \mathrm{eV})$ laser light. The Raman spectroscopy detects typical for the PMT/rGO/Ni complex regions with different relative concentrations of PMTs and rGO. For pristine PMTs, the Raman spectrum reveals several characteristic bands (spectrum $a$, Fig. S3 (ESI)), which can be assigned as follows. The bands at 1001 and $1031 \mathrm{~cm}^{-1}$ (recognized as the reference and normalization bands for the Raman spectra of protein), as well as bands at 1583 and $1604 \mathrm{~cm}^{-1}$ are attributed to the vibrations of the aromatic ring of $\operatorname{FF}[32,33]$. The group of intense high-frequency bands at about $3000 \mathrm{~cm}^{-1}$ is due to stretching vibrations of $\mathrm{CH}$ and $\mathrm{NH}$ bonds $[34,35]$. The amide III band $(\mathrm{C}-\mathrm{N}$ stretching and $\mathrm{N}-\mathrm{H}$ bending) can be found at $1250 \mathrm{~cm}^{-1}$, whereas amide I band ( $\mathrm{C}=0$ stretching) is at $1688 \mathrm{~cm}^{-1}$ [32]. The Raman spectrum of rGO/Ni regions (spectrum $d$, Fig. S3 (ESI)) reveals two strong bands at about 1348 and $1587 \mathrm{~cm}^{-1}$ as well as three broad high-frequency bands at 2690,2939, and $3239 \mathrm{~cm}^{-1}$. The G-band at $1587 \mathrm{~cm}^{-}$ ${ }^{1}$ is characteristic for all graphitic structures and originates from inplane vibration of $\mathrm{sp}^{2}$ bonded carbon atoms [36]. It is the only band coming from a normal first order Raman scattering process in graphene [30]. The D band at $1348 \mathrm{~cm}^{-1}$ and D' band appearing as a shoulder of the $G$ band at $1620 \mathrm{~cm}^{-1}$ are usually associated with the presence of various types of defects in the $\mathrm{sp}^{2}$ bonding $[29,36]$. The D-band overtone, $G^{\prime}$ band (also called 2D band), appears at $2690 \mathrm{~cm}^{-1}$, which is allowed without any kind of disorder or defects [30]. According to the study by Ferrari et al. [37], the observed position and the shape of this second-order peak (spectrum d, Fig. S3 (ESI)) obtained by 532-nm radiation corresponds to single-layer graphene. Another band, known as S3, at $2940 \mathrm{~cm}^{-1}$ is a second-order peak derived from the D-G peak combination [38-40]. The intensity ratios $\mathrm{I}_{\mathrm{D}} / \mathrm{I}_{\mathrm{G}}, \mathrm{I}_{\mathrm{D}^{\prime}} / \mathrm{I}_{\mathrm{G}}$, and $\mathrm{I}_{\mathrm{S} 3} / \mathrm{I}_{\mathrm{G}^{\prime}}$ can be used to qualitatively estimate the number of defects in these materials [39]. The average $\mathrm{I}_{\mathrm{D}} / \mathrm{I}_{\mathrm{G}}$ ratio for $\mathrm{PMT} / \mathrm{rGO} / \mathrm{Ni}$ is measured to be about $1.3-$ 1.5 , which is greater than that of 0.84 measured for pure GO (0.77 in Ref. [40]) and that of 0.97 measured for rGO (1.1 in Ref. [40]). This increase can be caused by the deoxygenation of GO into rGO, by decoration with $\mathrm{Ni}$ nanoparticles, and/or by interaction with FF PMT template. Finally, D' overtone, peak 2D', is visible at $3235 \mathrm{~cm}^{-1}$ [36]. Raman spectra $b$ and $c$ in Fig. S3 (ESI) originate from the PMTs/rGO/Ni complex as they show Raman features from both PMTs and rGO/Ni structures.

Fig. 3 presents an optical image and results of the Raman study of a single microtube partly-covered by rGO/Ni. Fig. 3(a) shows the Raman map obtained by integration of the most intense peak of PMT at 1001 $\mathrm{cm}^{-1}$ as well as the corresponding place on the optical image outlined by dashed line. The area with detectable Raman signal in the Raman map (bright region) corresponds to the position of the microtube visible in the optical image. Fig. 3(b) shows the Raman spectra from three characteristic regions of the studied area. The Raman spectrum from the platinum substrate exhibits only one broad feature at $770 \mathrm{~cm}^{-1}$ (spectrum 1). The Raman spectrum at position 2 mostly comes from the PMT (see also spectrum $a$ in Fig. S3 (ESI)). The largest contribution of rGO/Ni layer to the Raman spectrum is detected at position 3. It can be seen that the spectrum 3 is essentially a superposition of the spectrum 2 with two
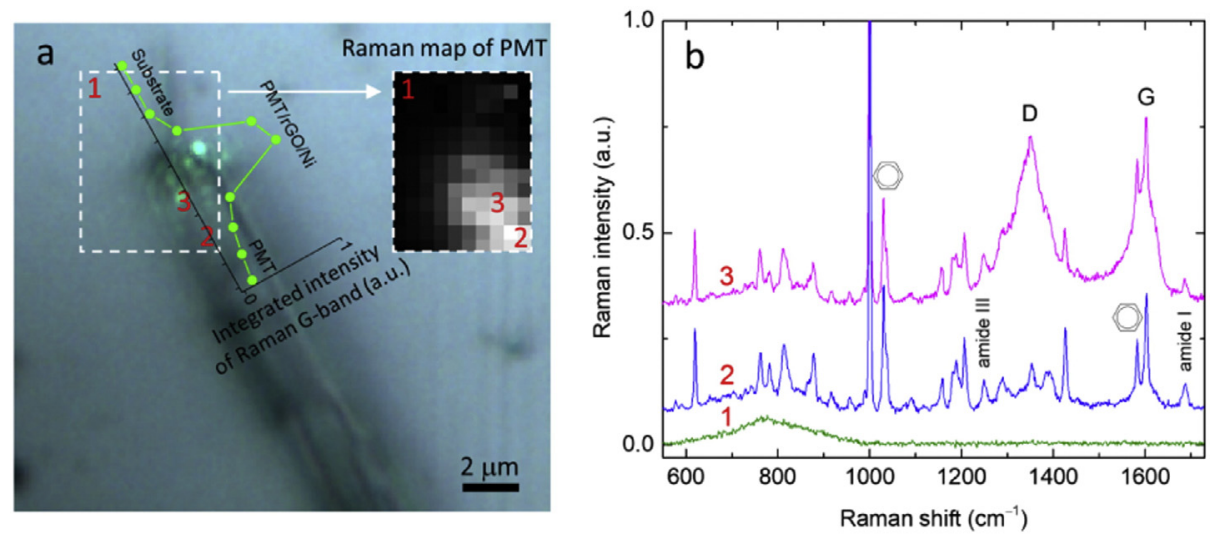

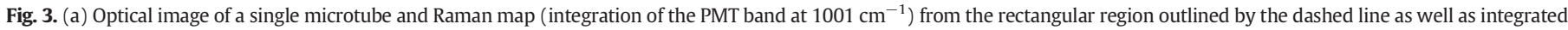

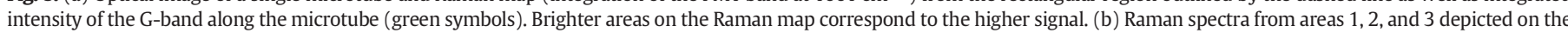
Raman map shown in panel $a$. 
broad D and G bands from the rGO/Ni structure. The same tendency can be observed in the Fig. S3 (ESI), i.e. the spectra $b$ and $c$ are obtained by superposition of spectra $a$ and $d$ with different coefficients. Thus, close similarities observed between micro-Raman spectra (i.e. the band positions and relative intensities related to PMTs) of the PMT/rGO/Ni and PMTs lead to the conclusion that the introduction of $\mathrm{rGO} / \mathrm{Ni}$ has no significant effect on the molecular structure or assembly mode of PMTs. A Raman line scan along the PMT has been carried out by measuring the spectra along straight line with a step of $1 \mu \mathrm{m}$ and plotting the area of the G-band (peak at $\sim 1587 \mathrm{~cm}^{-1}$ ) versus the coordinate (see Fig. $3(\mathrm{a})$ ). The resulting plot suggests that most of $\mathrm{rGO} / \mathrm{Ni}$ compound is located at the end part of the PMT, and the amount of the $\mathrm{rGO} / \mathrm{Ni}$ decreases towards the inner part of the PMT. These observations are consistent with the model of rGO/Ni gradient on top of upper PMT's hexagonal facet (Fig. 1(d)) proposed based on the SEM and XRD results.

Mechanical properties of the fabricated PMT/rGO/Ni structures were studied by HD-AFM (Fig. 4) based on the estimation of the attractive and repulsive forces between the sample and the tip $(D F L(z))$ [41]. For this study, the FF PMT with top face fully covered by $\mathrm{rGO} / \mathrm{Ni}$ composite was chosen (example of such covering is presented in Fig. S2(b) (ESI)). The rGO/Ni layer deposited on the top PMT facet manifests itself as a bright stripe seen in the stiffness (Fig. 4(d)), adhesion (Fig. 4(e)), and viscoelasticity (Fig. 4(f)) images. The results of the local mechanical measurements indicate that the adhesion ability of the PMT/rGO/Ni is about ten times greater than that inherent to the uncoated PMT facet (Fig. 4(e)). The stiffness data suggest that the mechanical stability of the PMT/rGO/Ni layer is around two times higher than that of the pristine PMT (Fig. 4(d)). The viscoelasticity data demonstrate a higher value for the PMT/rGO/Ni surface as compared to the pristine PMT facets (Fig. $4(f)$ ). Additional $\operatorname{DFL}(z)$ measurements have been done on pristine (point 1 in Fig. S4(a) (ESI)) and covered by rGO/Ni layer parts of microtube (point 2 in Fig. S4(a) (ESI)). The combination of data obtained via the analysis of attractive and repulsive forces demonstrates the apparent interaction of rGO/Ni layer with FF PMT revealed in pressing and adhesion forces changes appearing in $\operatorname{DFL}(z)$ dependences (Fig. S4(d, e) (ESI)). The morphological changes driven by the interaction are shown in Figs. S5 and S6 (ESI), where the cross-sections taken perpendicular and parallel to the FF PMT disclose a gradient in the coverage of the microtube by $\mathrm{rGO} / \mathrm{Ni}$ layer. All these data provide evidence supporting the deposition scheme presented in Fig. 1(d) (the latter suggests gradient deposition of $\mathrm{rGO} / \mathrm{Ni}$ along the peptide microtube). The results obtained are consistent with the theoretical predictions described by Han et al. [42], where the strength and resilience of the peptides were found to be greatly enhanced through their interaction with graphene. Accordingly, one can suppose that the rGO/Ni layer tends to participate in the peptide intramolecular interactions and integrates into the interchain of $\beta$-sheets in protein domains thus enhancing the stability of PMT/rGO/Ni structure [43].

Recently, we have reported enhanced electrical conductivity of rGO matrix due to the decoration with Ni nanoparticles [7]. Accordingly, the main idea behind the integration of $\mathrm{rGO} / \mathrm{Ni}$ with PMTs was an attempt to increase the negligible conductivity of FF peptide microtubes [44]. Moreover, a combination of FF PMT with $\mathrm{rGO} / \mathrm{Ni}$ increases the electron affinity of such system thus promoting the creation of high efficient hybrid energy harvesting system similar to that proposed by Kim et al. [22]. In order to evaluate the electrical properties of the composites, EFM and KPFM studies have been performed. EFM and KPFM are known as the principal methods allowing the electric field and surface potential distributions to be evaluated with the nanoscale resolution [45]. These techniques are frequently used for various composite systems due to the direct and quantitative measurement of the charge and work function values [45]. Fig. 5 summarizes the results of EFM study showing a clear difference between the electron affinity of the FF PMT and $\mathrm{rGO} / \mathrm{Ni}$ and a uniform nature of the $\mathrm{rGO} / \mathrm{Ni}$ layer without charge traps, debris, etc. in the electric field distribution (Fig. 5(d)).
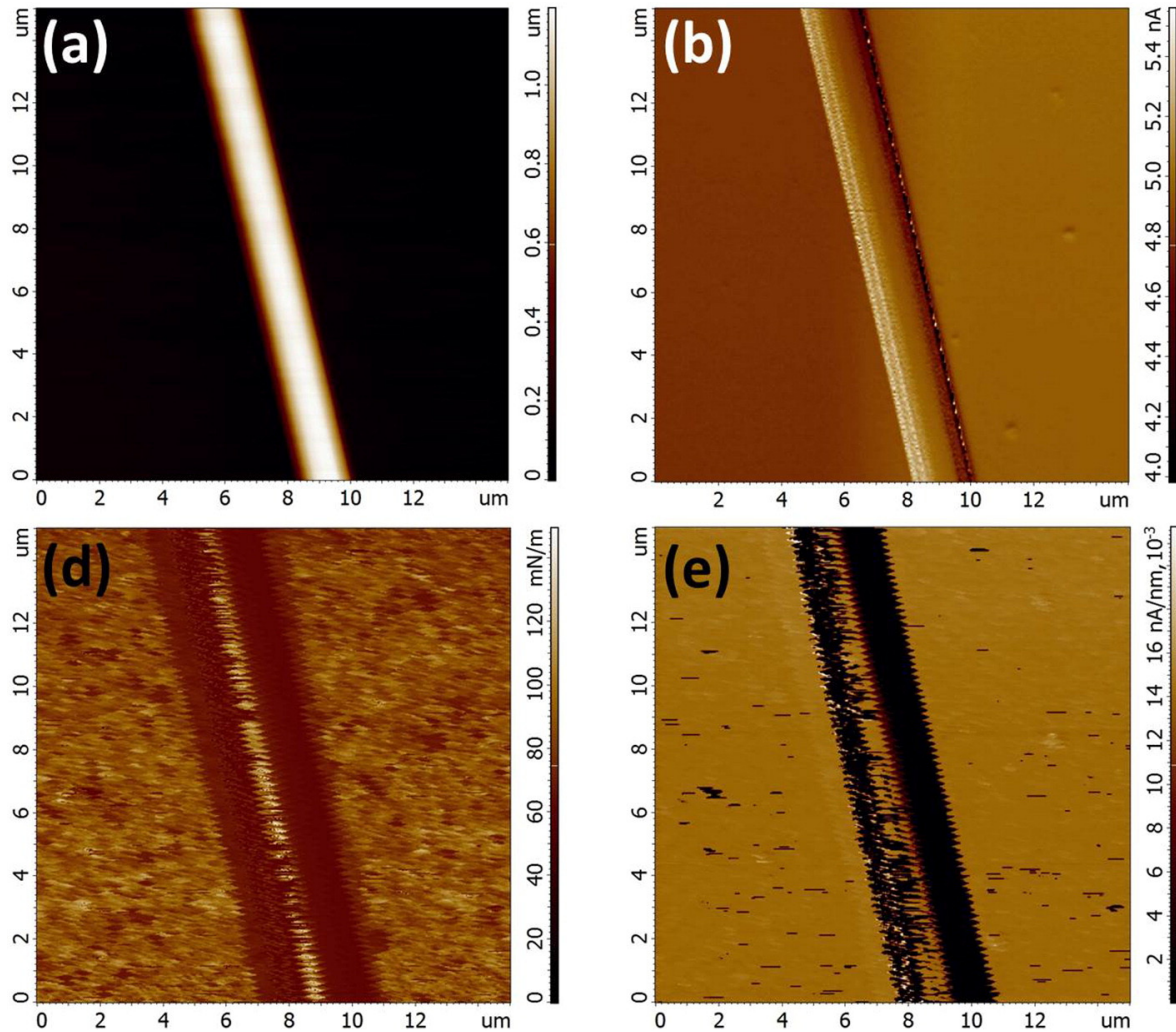
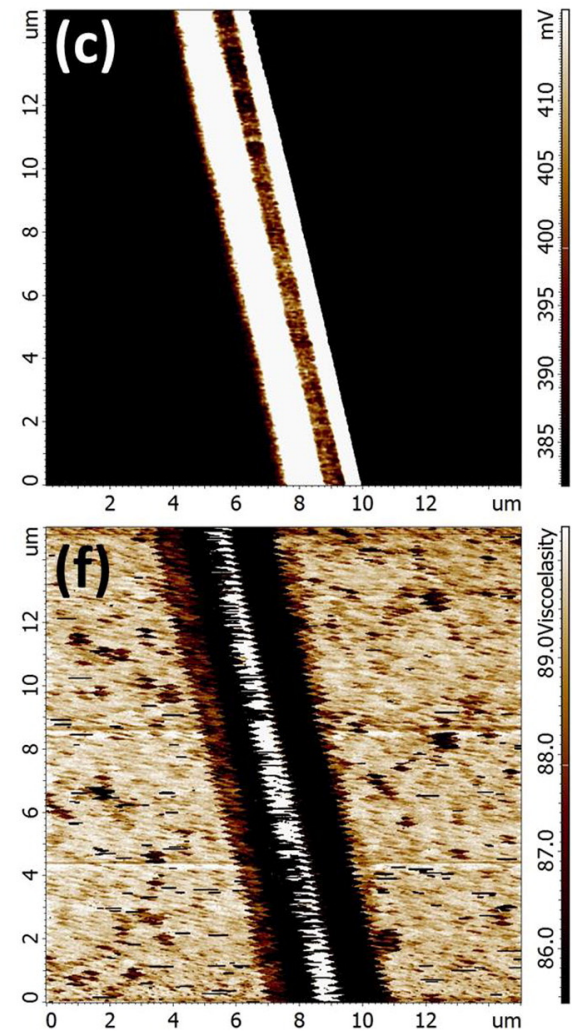

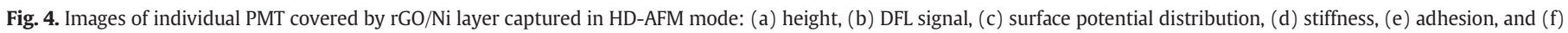
viscoelasticity. 

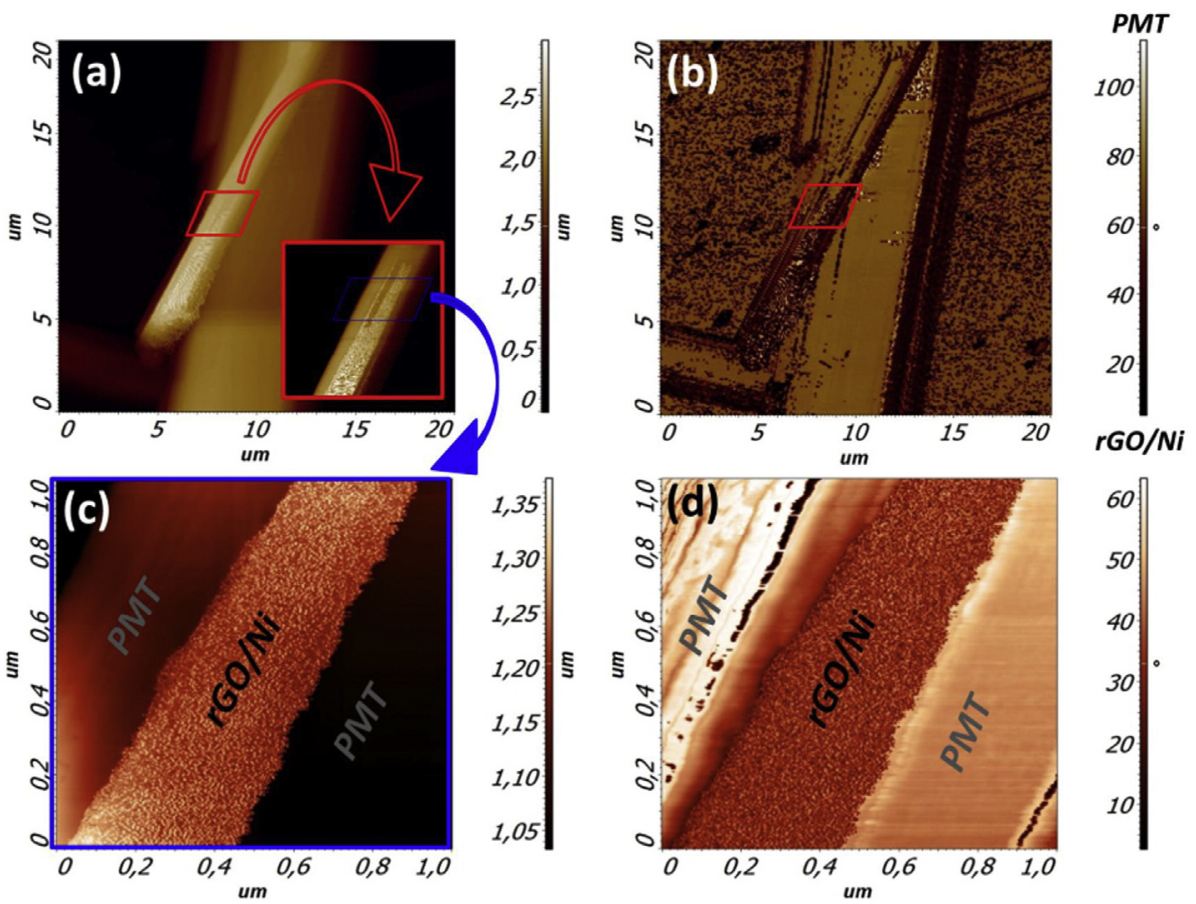

Fig. 5. EFM measurements: (a, c) topography, (b, d) EFM response.

Work function (WF) analysis of the PMT/rGO/Ni structure was done by using the KPFM method (Fig. 6). The difference between the work functions of $\mathrm{rGO} / \mathrm{Ni}$ and $\mathrm{Pt}$ substrate was experimentally measured to be about $0.6 \mathrm{eV}$ (Fig. 6(d)). According to the recommended values for WFs $[7,46]$ (Table 1 ), the work function of rGO/Ni layer deposited on top of PMT was calculated to be about $4.9 \mathrm{eV}$ relative to Pt substrate,

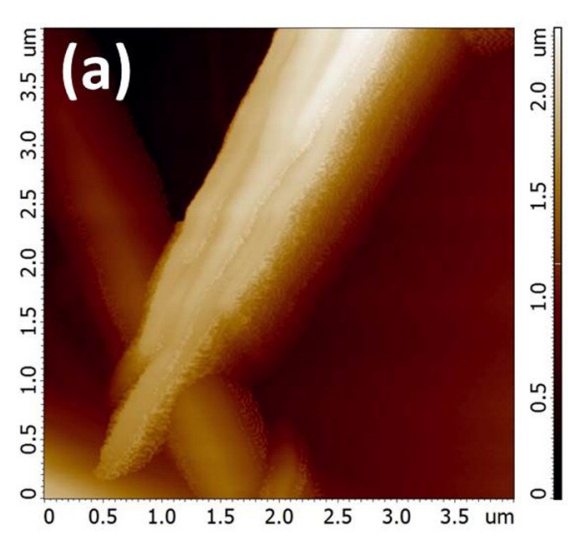

(d)

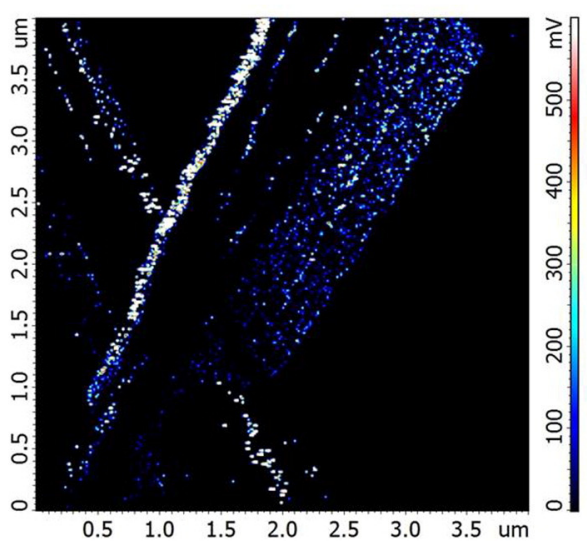

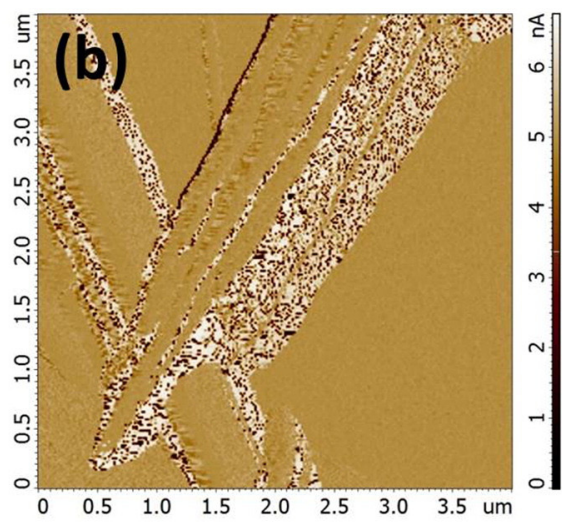

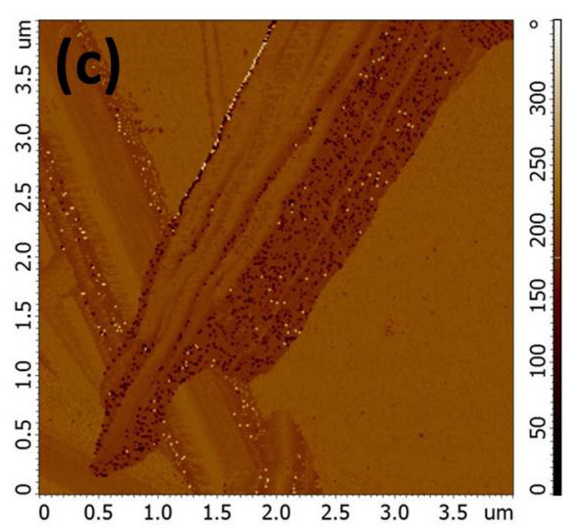

(e)

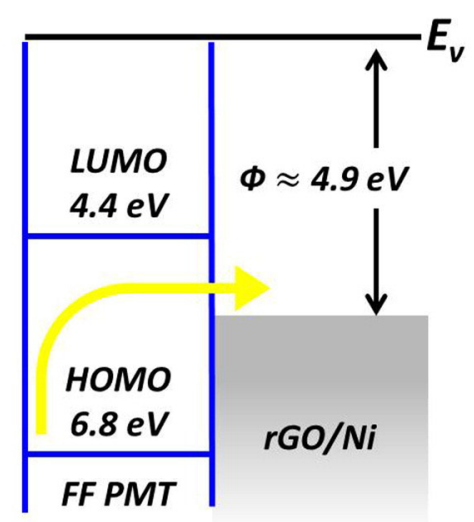

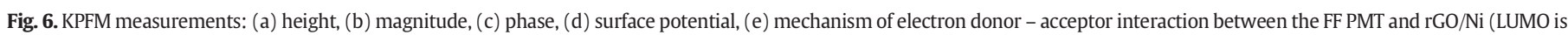
the lowest unoccupied molecular orbital and HOMO is the highest occupied molecular orbital). 
Table 1

Recommended work functions for polycrystalline materials [7, 46].

\begin{tabular}{ll}
\hline Material (polycrystalline) & Work function, eV \\
\hline$P t$ & $5.5 \pm 0.4$ \\
$N i$ & $5.2 \pm 0.2$ \\
$r G O$ & $4.30 \pm 0.08$ \\
Graphite & $4.61 \pm 0.34$ \\
\hline
\end{tabular}

thus being in agreement with the earlier measurements on pure $\mathrm{rGO} / \mathrm{Ni}$ composite [7].

In general, the mechanism of electron donor - acceptor interactions between graphene-based materials and peptides has been discussed for aromatic amino acids [1] and reduced nicotinamide adenine dinucleotides [2-6, 22], which can be potentially used in electrochemical sensing and energy harvesting applications. The schematic of the electron donor - acceptor interactions in the PMT/rGO/Ni system is presented in Fig. 6(e) (the HOMO and LUMO states for pristine PMT ( $6.8 \mathrm{eV}$ and $4.4 \mathrm{eV}$, respectively) were taken from Ref. [47]). This interaction is very efficient for energy harvesting by artificial photosynthesis [47, 48]. The band gap between HOMO and LUMO states in pure FF PMTs was found to be in the range of $2.4 \mathrm{eV}$ to $3 \mathrm{eV}[47,48]$. Our KPFM data indicate that the energy band gap is narrowed due to the PMT and $\mathrm{rGO} / \mathrm{Ni}$ interaction (Fig. 6(e)). The PMT/rGO/Ni system satisfies the conditions for the light excitation-[47, 48] making a charge transfer from the HOMO to rGO/Ni energy states highly efficient (Fig. 6(e)).

The conductivity of the PMT/rGO/Ni system was studied with a local current measurement technique implemented in the contact AFM mode (c-AFM) with the grounded substrate. Fig. 7(a) shows the phase of semicontact AFM mode image (the height and magnitude are presented in Fig. S4(a, b) (ESI)) of PMT covered by the rGO/Ni layer having a thickness gradient (the bright contrast corresponds to uncovered PMT facet). In agreement with the existence of the $\mathrm{rGO} / \mathrm{Ni}$ component gradient, the local current was growing from $<0.1 \mathrm{nA}$ to $25 \mathrm{nA}$ (Fig. 7(c)) while the probe was moving towards the edge of the peptide microtube, where the concentration of $\mathrm{rGO} / \mathrm{Ni}$ component was supposed to attain a maximum value (Fig. 7(a, b)).
At the point with a maximal rGO/Ni concentration (Fig. 7(a, b)), the I-V dependences were obtained. Fig. 7(d) shows the nonlinear current behavior for the forward and backward I-V curves. The observed nonlinearity is directly associated with the $\mathrm{rGO} / \mathrm{Ni} / \mathrm{Pt}_{\text {tip }}$ interface properties described in our previous work [7]. By using the I-V data, the electrical conductivity of the $\mathrm{rGO} / \mathrm{Ni} / \mathrm{Pt}_{\text {tip }}$ contact was calculated to be about $\sim 800$ $\mathrm{S} / \mathrm{cm}$. This value is comparable with that characteristic of the materials used as metal-based current collectors in printed microelectronics [49]. This fact makes the $\mathrm{PMT} / \mathrm{rGO} / \mathrm{Ni} / \mathrm{Pt}_{\text {tip }}$ contact potentially applicable as local current drain and collector elements in embedded bioinspired structures.

Finally, PFM study was carried out to investigate the piezoelectric response in the modified FF PMT structures. It has been previously found that FF PMTs demonstrate only in-plane (IP) piezoelectric activity and show no out-of-plane (OOP) PFM signal [18]. The graphene based materials exhibit weak vertical deformations under applied voltage only after chemical or structural modification [28]. In this work, we report on strong simultaneous in-plane and out-of-plane piezoelectric responses in the PMT/rGO/Ni structures. Fig. 8(a-c) shows the topography of two quasi crossed microtubes and the corresponding OOP and IP PFM images. One can see a clear difference in the IP piezoresponse attributed to the phase shift taking place upon rotation of PMT, i.e. the angular dependence of the IP phase (Fig. 8(b)). This result is consistent with the previous data obtained for peptide micro- and nanotubes [18]. What is more remarkable, a strong vertical piezoresponse has also been detected (Fig. 8(c)). High resolution PFM measurements carried out on the PMT/rGO/Ni structure marked by red square (Fig. 8(a)) confirm the existence of the simultaneous IP and OOP piezoelectric responses (Fig. 8(e, f)). The maximal effective OOP and IP piezo-coefficients were calculated as about $\sim 12 \mathrm{pm} / \mathrm{V}$ and $18 \mathrm{pm} / \mathrm{V}$, respectively.

The XRD and micro-Raman analysis demonstrates that the deposition of rGO/Ni layer does not change the chemical, molecular and structural properties of PMTs. Accordingly, the observed PFM response should originate from the interaction between $\mathrm{rGO} / \mathrm{Ni}$ and FF PMT, although neither rGO/Ni nor FF PMT have out-of-plane component of piezotensor. Moreover, we have verified the absence of any PFM response for rGO/Ni component alone [7]. Consequently, the piezoelectric

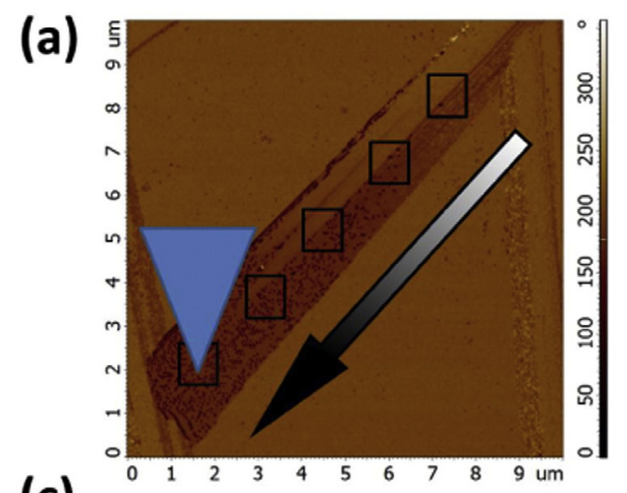

(b)
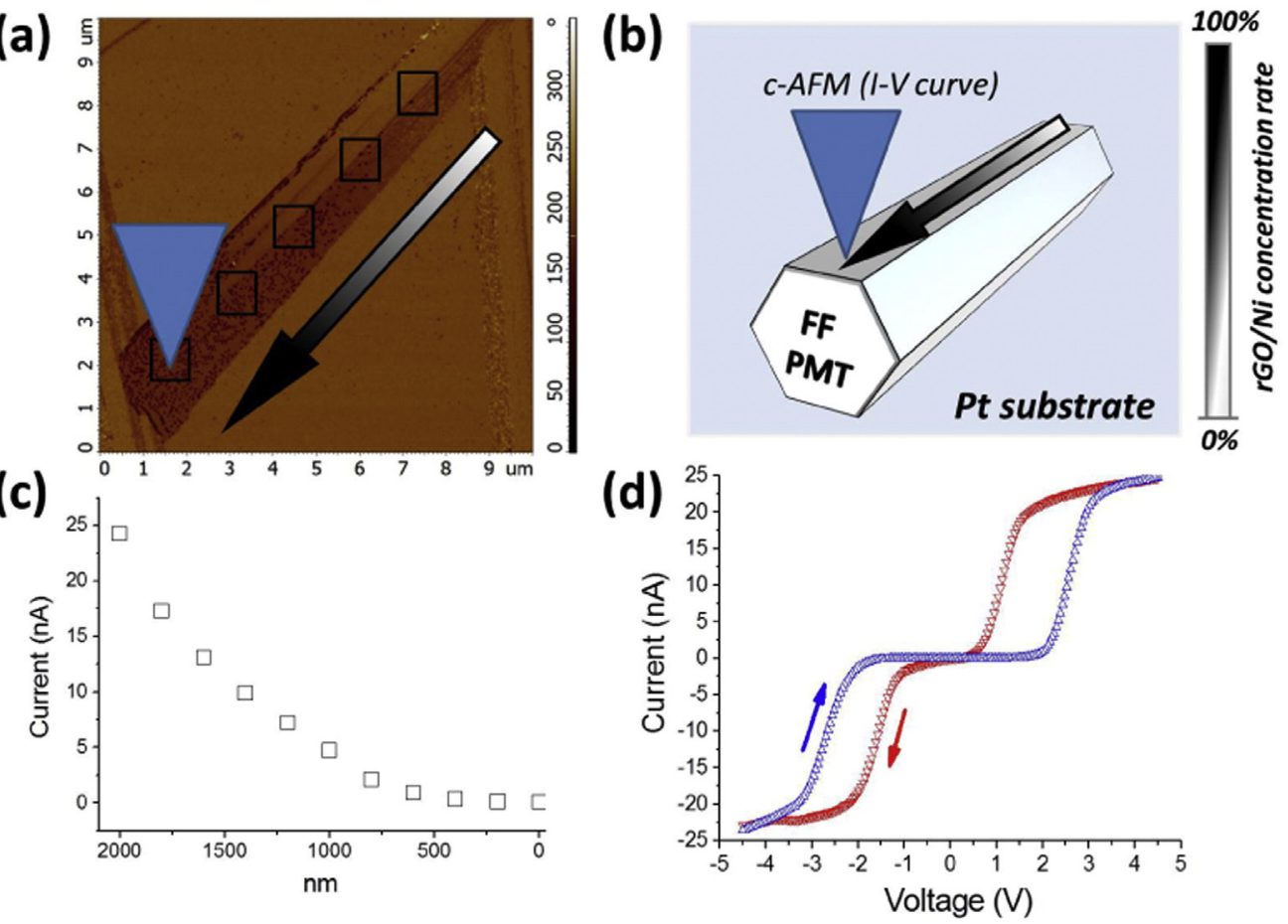

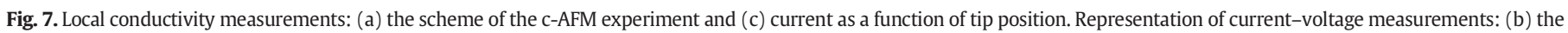
scheme illustrating the tip position and (d) experimental results. 

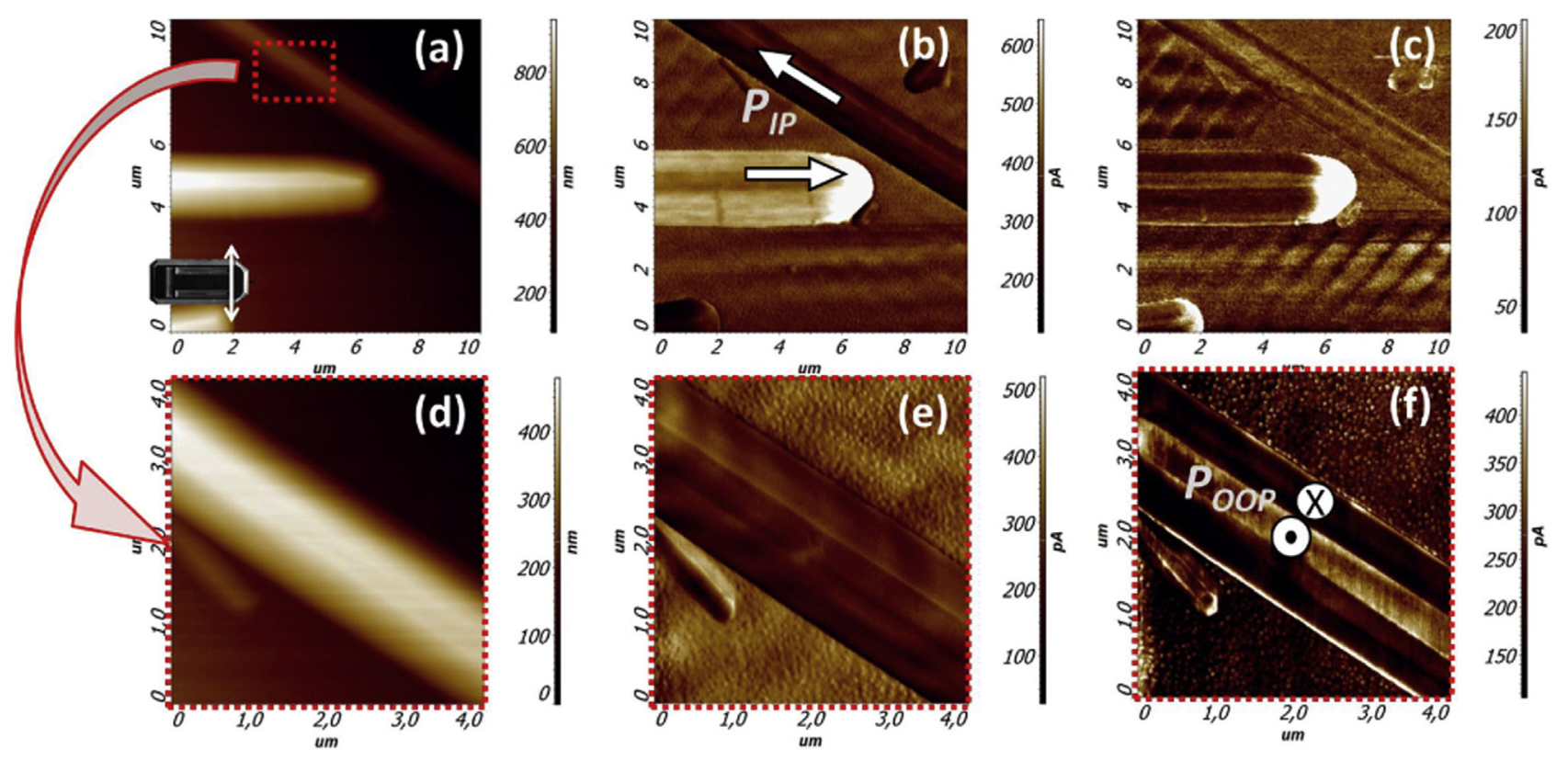

Fig. 8. PFM measurements: (a, d) topography, (b, e) in-plane piezoresponse, (c, f) out-of-plane piezoresponse.

response in the $\mathrm{PMT} / \mathrm{rGO} / \mathrm{Ni}$ structure should be associated with $\mathrm{FF}$ PMT, whose interface is modified due to the presence of rGO/Ni component. In other words, we believe that the graphene based compound induces the cooperative IP and OOP piezoresponses in PMTs, similarly to the behavior of $\mathrm{GO} / \mathrm{SiO}_{2}[28]$.

Apparently, the explanation of the phenomena described lies in the interaction between the rGO/Ni and FF PMT. In general, the interactions between graphene-based materials and polymers are controlled by the weak van der Waals forces, $\pi-\pi$ stacking and hydrophobic-hydrophobic interactions [50]. For our hybrid system we admit the following important interactions which possibly contribute to the functionality of PMT/ rGO/Ni complex: $\pi-\pi$ stacking (the interaction between electron-rich aromatic rings of rGO and phenyl rings of diphenylalanine) could impact the vertical (radial) PFM signal; the electrostatic interaction restorability during variable strain loading could increase the stiffness and adhesion forces; and hydrogen bonding (the interaction between oxygen functional groups at the edges of rGO matrix and phenyl rings of diphenylalanine) could induce the polar interactions [50-52].

\section{Conclusions}

In this work we have presented a simple method of controlled macroscopic integration of rGO decorated by nickel nanoparticles with selfassembled FF dipeptides. The XRD and micro-Raman data suggest that the introduction of the rGO/Ni composite does not induce any significant changes in the molecular structure or assembly mode of the PMTs. The effect of graphene nanocomposite on the properties of PMTs has been investigated by SEM and SPM techniques. An enhanced mechanical stability of the modified PMTs has been revealed. An increase in the conductivity of PMTs due to the deposition of $\mathrm{rGO} / \mathrm{Ni}$ has been found. The KPFM study has allowed us to evaluate the energy band states and work function in the PMT/rGO/Ni structures and confirm their practical usability. Extraordinary out-of-plane piezoelectric response has also been discovered. The $\pi-\pi$ stacking, electrostatic and hydrogen bonding interactions between graphene-based and polypeptide materials have been proposed as the possible origins of the properties described. The synergistic effect of FF PMTs and rGO/Ni described in this work can pave the way for designing high-performance applications in the fields of energy harvesting and bio-inspired microelectronics.

\section{Acknowledgments}

M. S. I. is grateful to the Fundaçao para a Ciencia e Tecnologia (FCT) for financial support through the project MATIS - Materiais e Tecnologias Industriais Sustentáveis (CENTRO-01-0145-FEDER000014). V. A. K. is grateful to FCT for financial support through the FCT Investigator Programme (project IF/00819/2014/CP1223/CT0011). M. S. is grateful to the FCT for the PhD grant (SFRH/BD/98337/2013). T. N. is grateful to FCT for financial support through the project PTDC/ QEQ-QFI/3284/2014. S.K, F.S and A.K thank the joint project PortugalTurkey TUBITAK/0006/2014 and No. 115F227. A. K. acknowledges the support of CICECO-Aveiro Institute of Materials (Ref. FCT UID/CTM/ $50011 / 2013$ ) financed by national funds through the FCT/MEC and, when applicable, co-financed by FEDER under the PT2020 Partnership Agreement. A. M. B. and E. D. M. express their gratitude to the Russian Ministry of Education and Science (Grant No. 14.Z50.31.0034 and the State Task No. 3.1923.2017/4.6) for supporting this study. P.A.A.P.M. acknowledges the FCT/MCTES for a research contract under the Program Investigador IF/00917/2013/CP1162/CT0016 and TEMA (PEst-C/EME/ UI0481/2013. Access to TAIL-UC facility funded under QREN-Mais Centro project ICT_2009_02_012_1890 is gratefully acknowledged. The Coimbra Chemistry Centre is supported by the FCT through the project UI0313/QUI/2013 co-funded by COMPETE-UE.

\section{Conflicts of interest}

There are no conflicts of interest to declare.

\section{Appendix A. Supplementary data}

Supplementary data to this article can be found online at https://doi. org/10.1016/j.matdes.2018.01.018.

\section{References}

[1] A.S. Tayi, A. Kaeser, M. Matsumoto, T. Aida, S.I. Stupp, Supramolecular ferroelectrics, Nat. Chem. 7 (2015) 281-294.

[2] G. Chang, X. Zhu, A. Li, W. Kan, R. Warren, R. Zhao, X. Wang, G. Xue, J. Shen, L. Lin Formation and self-assembly of 3D nanofibrous networks based on oppositely charged jets, Mater. Des. 97 (2016) 126-130.

[3] C.-L. Xu, Y.-Z. Wang, Self-assembly of stearic acid into nano flowers induces the tunable surface wettability of polyimide film, Mater. Des. 138 (2018) 30-38. 
[4] Y. Wang, Y. Yu, X. Hu, A. Feng, F. Jiang, L. Song, p-Phenylenediamine strengthened graphene oxide for the fabrication of superhydrophobic surface, Mater. Des. 127 (2017) 22-29.

[5] J. Montenegro, C. Vázquez-Vázquez, A. Kalinin, K.E. Geckeler, J.R. Granja, Coupling of carbon and peptide nanotubes, J. Am. Chem. Soc. 136 (2014) 2484-2491.

[6] P. Li, X. Chen, W. Yang, Graphene-induced self-assembly of peptides into macroscopic-scale organized nanowire arrays for electrochemical NADH sensing, Langmuir 29 (2013) 8629-8635.

[7] M. Salimian, M. Ivanov, F.L. Deepak, D.Y. Petrovykh, I. Bdikin, M. Ferro, A. Kholkin, E Titus, G. Goncalves, Synthesis and characterization of reduced graphene oxide/spiky nickel nanocomposite for nanoelectronic applications, J. Mater. Chem. C 3 (2015) 11516-11523.

[8] F. Lu, S. Zhang, H. Gao, H. Jia, L. Zheng, Protein-decorated reduced oxide graphene composite and its application to SERS, ACS Appl. Mater. Interfaces 4 (2012) 3278-3284.

[9] Y. Maeda, J. Higo, Y. Amagai, J. Matsui, K. Ohkubo, Y. Yoshigoe, M. Hashimoto, K. Eguchi, M. Yamada, T. Hasegawa, Y. Sato, J. Zhou, J. Lu, T. Miyashita, S. Fukuzumi, T. Murakami, K. Tohji, S. Nagase, T. Akasaka, Helicity-selective photoreaction of single-walled carbon nanotubes with organosulfur compounds in the presence of oxygen, J. Am. Chem. Soc. 135 (2013) 6356-6362.

[10] D.A. Britz, A.N. Khlobystov, Noncovalent interactions of molecules with single walled carbon nanotubes, Chem. Soc. Rev. 35 (2006) 637.

[11] G. Goncalves, P.A.A.P. Marques, C.M. Granadeiro, H.I.S. Nogueira, M.K. Singh, J. Grácio, Surface modification of graphene nanosheets with gold nanoparticles: the role of oxygen moieties at graphene surface on gold nucleation and growth, Chem. Mater. 21 (2009) 4796-4802.

[12] A. Heredia, I. Bdikin, S. Kopyl, E. Mishina, S. Semin, A. Sigov, K. German, V. Bystrov, J Gracio, A.L. Kholkin, Temperature-driven phase transformation in self-assembled diphenylalanine peptide nanotubes, J. Phys. D. Appl. Phys. 43 (2010), 462001.

[13] C.H. Görbitz, The structure of nanotubes formed by diphenylalanine, the core recognition motif of Alzheimer's $\beta$-amyloid polypeptide, Chem. Commun. (2006) 2332-2334.

[14] C. Ehli, C. Oelsner, D.M. Guldi, A. Mateo-Alonso, M. Prato, C. Schmidt, C. Backes, F. Hauke, A. Hirsch, Manipulating single-wall carbon nanotubes by chemical doping and charge transfer with perylene dyes, Nat. Chem. 1 (2009) 243-249.

[15] J. Montenegro, M.R. Ghadiri, J.R. Granja, Ion channel models based on self-assembling cyclic peptide nanotubes, Acc. Chem. Res. 46 (2013) 2955-2965.

[16] K.A.C. Glazner, G.L. Odero, E. Anema, A. Motnenko, J. Schapansky, D. Grossman, D.R Oliver, G.W. Glazner, B.C. Albensi, Strain specific differences in memory and neuropathology in a mouse model of Alzheimer's disease, Life Sci. 86 (2010) 942-950.

[17] A.T. Petkova, R.D. Leapman, Z. Guo, W.-M. Yau, M.P. Mattson, R. Tycko, Self-propagating, molecular-level polymorphism in Alzheimer's $\beta$-amyloid fibrils, Science 307 (2005) 262-265.

[18] A. Kholkin, N. Amdursky, I. Bdikin, E. Gazit, G. Rosenman, Strong piezoelectricity in bioinspired peptide nanotubes, ACS Nano 4 (2010) 610-614.

[19] Y. Kuang, Y. Gao, B. Xu, Supramolecular hydrogelators of N-terminated dipeptides selectively inhibit cancer cells, Chem. Commun. 47 (2011) 12625-12627.

[20] S.K.M. Nalluri, C. Berdugo, N. Javid, P.W.J.M. Frederix, R.V. Ulijn, Biocatalytic self-assembly of supramolecular charge-transfer nanostructures based on n-type semiconductor-appended peptides, Angew. Chem. Int. Ed. 53 (2014) 5882-5887.

[21] Y. Shen, X. Fu, W. Fu, Z. Li, Biodegradable stimuli-responsive polypeptide materials prepared by ring opening polymerization, Chem. Soc. Rev. 44 (2015) 612-622.

[22] J.H. Kim, M. Lee, J.S. Lee, C.B. Park, Self-assembled light-harvesting peptide nanotubes for mimicking natural photosynthesis, Angew. Chem. Int. Ed. 51 (2012) 517-520.

[23] Y. Wang, J. Liu, L. Liu, D. Sun, High-quality reduced graphene oxide-nanocrystalline platinum hybrid materials prepared by simultaneous co-reduction of graphene oxide and chloroplatinic acid, Nanoscale Res. Lett. 6 (2011) 241.

[24] S. Sun, C.B. Murray, D. Weller, L. Folks, A. Moser, Monodisperse FePt nanoparticles and ferromagnetic FePt nanocrystal Superlattices, Science 287 (2000) 1989-1992.

[25] H.S. Yaddanapudi, K. Tian, S. Teng, A. Tiwari, Facile preparation of nickel/carbonize wood nanocomposite for environmentally friendly supercapacitor electrodes, Sci. Rep. 6 (2016), 33659.

[26] A.C. Ferrari, D.M. Basko, Raman spectroscopy as a versatile tool for studying the properties of graphene, Nat. Nanotechnol. 8 (2013) 235-246.

[27] K. Ryan, S.M. Neumayer, H.V.R. Maraka, A.L. Kholkin, J.H. Rice, B.J. Rodriguez, Thermal and aqueous stability improvement of graphene oxide enhanced diphenylalanine nanocomposites, Sci. Technol. Adv. Mater. 18 (2017) 172-179.
[28] G. da Cunha Rodrigues, P. Zelenovskiy, K. Romanyuk, S. Luchkin, Y. Kopelevich, A. Kholkin, Strong piezoelectricity in single-layer graphene deposited on $\mathrm{SiO}_{2}$ grating substrates, Nat. Commun. 6 (2015) 7572.

[29] A. Eckmann, A. Felten, A. Mishchenko, L. Britnell, R. Krupke, K.S. Novoselov, C. Casiraghi, Probing the nature of defects in graphene by Raman spectroscopy, Nano Lett. 12 (2012) 3925-3930.

[30] L.M. Malard, M.A. Pimenta, G. Dresselhaus, M.S. Dresselhaus, Raman spectroscopy in graphene, Phys. Rep. 473 (2009) 51-87.

[31] X. Díez-Betriu, S. Álvarez-García, C. Botas, P. Álvarez, J. Sánchez-Marcos, C. Prieto, R. Menéndez, A. de Andrés, Raman spectroscopy for the study of reduction mechanisms and optimization of conductivity in graphene oxide thin films, J. Mater. Chem. C 1 (2013) 6905.

[32] B. Lekprasert, V. Korolkov, A. Falamas, V. Chis, C.J. Roberts, S.J.B. Tendler, I. Notingher, Investigations of the supramolecular structure of individual diphenylalanine nanoand microtubes by polarized Raman microspectroscopy, Biomacromolecules 13 (2012) 2181-2187.

[33] B. Hernández, F. Pflüger, S.G. Kruglik, M. Ghomi, Characteristic Raman lines of phenylalanine analyzed by a multiconformational approach, J. Raman Spectrosc. 44 (2013) 827-833.

[34] B. Ravikumar, R.K. Rajaram, V. Ramakrishnan, Raman and IR spectral studies of Lphenylalanine L-phenylalaninium dihydrogenphosphate and DL-phenylalaninium dihydrogenphosphate, J. Raman Spectrosc. 37 (2006) 597-605.

[35] P.S. Zelenovskiy, A.O. Davydov, A.S. Krylov, A.L. Kholkin, Raman study of structural transformations in self-assembled diphenylalanine nanotubes at elevated temperatures, J. Raman Spectrosc. 48 (2017) 1401-1405.

[36] R. Bajpai, S. Roy, N. kulshrestha, J. Rafiee, N. Koratkar, D.S. Misra, Graphene supported nickel nanoparticle as a viable replacement for platinum in dye sensitized solar cells, Nano 4 (2012) 926-930.

[37] A.C. Ferrari, J.C. Meyer, V. Scardaci, C. Casiraghi, M. Lazzeri, F. Mauri, S. Piscanec, D. Jiang, K.S. Novoselov, S. Roth, A.K. Geim, Raman spectrum of graphene and graphene layers, Phys. Rev. Lett. 97 (2006), 187401.

[38] F.T. Johra, J.W. Lee, W.G. Jung, Facile and safe graphene preparation on solution based platform, J. Ind. Eng. Chem. 20 (2014) 2883-2887.

[39] H. Wang, J.T. Robinson, X. Li, H. Dai, Solvothermal reduction of chemically exfoliated graphene sheets, J. Am. Chem. Soc. 131 (2009) 9910-9911.

[40] I.K. Moon, J. Lee, R.S. Ruoff, H. Lee, Reduced graphene oxide by chemical graphitization, Nat. Commun. 1 (2010) 73.

[41] https://www.ntmdt-si.com/hybrid-mode-afm.

[42] S. Gurunathan, J.W. Han, E. Kim, J.H. Park, J.-H. Kim, Reduction of graphene oxide by resveratrol: a novel and simple biological method for the synthesis of an effective anticancer nanotherapeutic molecule, Int. J. Nanomedicine 10 (2015) 2951.

[43] Y. Zhao, Y. Sha, Q. Lin, Y. Zhong, M.O. Tade, Z. Shao, Facile conversion of commercial coarse-type $\mathrm{LiCoO}_{2}$ to nanocomposite-separated Nanolayer architectures as a way for electrode performance enhancement, ACS Appl. Mater. Interfaces 7 (2015) 1787-1794.

[44] L. Adler-Abramovich, E. Gazit, The physical properties of supramolecular peptide assemblies: from building block association to technological applications, Chem. Soc. Rev. 43 (2014) 6881-6893.

[45] S. Kalinin, A. Gruverman (Eds.), Scanning probe microscopy, Springer, New York, 2007.

[46] D.R. Lide, CRC Handbook of Chemistry and Physics, 86th ed.3-140, CRC Press, 2005.

[47] T. Nikitin, S. Kopyl, V.Y. Shur, Y.V. Kopelevich, A.L. Kholkin, Low-temperature photoluminescence in self-assembled diphenylalanine microtubes, Phys. Lett. A 380 (2016) 1658-1662.

[48] V.S. Bystrov, I.K. Bdikin, A. Heredia, R.C. Pullar, E.D. Mishina, A.S. Sigov, A.L. Kholkin, Piezoelectricity and ferroelectricity in biomaterials: from proteins to self-assembled peptide nanotubes, in: G. Giofani, A. Menciassi (Eds.), Piezoelectric Nanomater. Biomed. Appl, Springer 2012, pp. 187-211.

[49] P.T. Moseley, J. Garche (Eds.), Electrochemical Energy Storage for Renewable Sources and Grid Balancing, 1st ed.Elsevier, 2016.

[50] K. Hu, D.D. Kulkarni, I. Choi, V.V. Tsukruk, Graphene-polymer nanocomposites for structural and functional applications, Prog. Polym. Sci. 39 (2014) 1934-1972.

[51] H. Wang, Q. Hao, X. Yang, L. Lu, X. Wang, Effect of graphene oxide on the properties of its composite with polyaniline, ACS Appl. Mater. Interfaces 2 (2010) 821-828.

[52] Y. Cheng, L.-D. Koh, D. Li, B. Ji, Y. Zhang, J. Yeo, G. Guan, M.-Y. Han, Y.-W. Zhang, Peptide-graphene interactions enhance the mechanical properties of silk fibroin, ACS Appl. Mater. Interfaces 7 (2015) 21787-21796. 